\title{
A Study on the Translation Strategies of Domestic Cosmetic Brand Names from the Perspective of Skopos Theory
}

\author{
Fei Sun \\ Tianjin University, Tianjin, China \\ Email: sunfei_98@tju.edu.cn
}

How to cite this paper: Sun, F. (2021) A Study on the Translation Strategies of Domestic Cosmetic Brand Names from the Perspective of Skopos Theory. Open Access Library Journal, 8: e7351.

https://doi.org/10.4236/oalib.1107351

Received: March 25, 2021

Accepted: April 23, 2021

Published: April 26, 2021

Copyright $\odot 2021$ by author(s) and Open Access Library Inc.

This work is licensed under the Creative Commons Attribution International License (CC BY 4.0).

http://creativecommons.org/licenses/by/4.0/ (c) (i) Open Access

\begin{abstract}
After its entry into the World Trade Organization (WTO), China has opened wider to the outside world. As a result, a growing number of foreign cosmetic companies have expanded their presence in China. By contrast, Chinese domestic cosmetics not only don't have an edge in its home market, but also fail to go global. The reasons are manifold. But their translations are also very important. Guided by Skopos Theory, this thesis believes that translation is across-cultural communicative activity with a certain purpose. The skopos rule should be put on the top priority. Through the investigation of various translation examples, the author believes that Skopos Theory can be used to guide the translation of different Chinese cosmetic brand names. Besides, the author also holds that translation strategies should be different according to the purpose of translation. By doing so, the author hopes to transcend cultural differences and disagreements so as to make domestic cosmetic products more competitive in the international arena.
\end{abstract}

\section{Subject Areas}

Linguistics

\section{Keywords}

Skopos Theory, Domestic Cosmetic Brand Names, Translation Strategies

\section{Introduction}

Since the implementation of reform and opening-up policy in 1978, China has seen the flourishing of foreign products in its domestic market. Since 2001, the number of foreign enterprises above designated size in China has reached a 
staggering 76,249 in 2009, and the proportion of foreign enterprises in China's industrial enterprises above designated size has hit a peak of $20.72 \%$ in 2005 (Xie \& Gao, 2019) [1]. As a result, foreign cosmetic brands gained a foothold in China by capturing the eye of the Chinese customer. Coca-Cola is a shining example. It is not only a leader in the industry, but also establishes a good brand power and influence among consumers, with its presence throughout China (Zhang, 2020) [2]. The success of these cosmetic companies can be attributed to several factors, such as quality, price as well as well-designed advertisements, etc (Zhong, 2016) [3]. The translation of cosmetic brand names also is part of the success story of these enterprises. A good translation can, at first, make an impressive impression on consumers and arouse their curiosity of the products.

Take the translation of a foreign domestic brand name as an example. As a skincare brand, ORIGINS of the US aims to provide its consumers a high-end product that is useful and natural, without any additives. It is translated into “悦 木之源” in Chinese, which demonstrates that its products are drawn from nature, thus attracting increasingly more customers to buy its products. If it is translated into “起源” in Chinese, many people will feel confused as to what it means. Brand name translation, therefore, is part of a company's success story.

Skopos Theory is one of the approaches to translation, which is proposed and then developed by many scholars like Katharina Reiss, Hans Vermeer and Christiane Nord. This theory assumes that a translation always has an aim, which is the decisive factor influencing the translator's decisions (Zhang \& Peng, 2015) [4]. The skopos rule must be placed first among the three basic rules of Skopos Theory. As a business translation, the translation of cosmetic brand names has its specific purpose. That is, to draw target readers' attention and cheers them to buy more products. The Skopos Theory, therefore, can be used to guide the translation of Chinese cosmetic brand names.

This thesis is composed of five chapters. Part one is the introduction, including the research background and basic contents of this thesis. Part two is the literature review. It tells how Skopos Theory has evolved into what it is today, with the emphasis on three cardinal rules and the strengths and limitations of this theory. Part three is an introduction of cosmetic brand names and their translation, focusing on the definition, formation and function of brand names as well as the importance of brand name translation. Part four is about how Skopos Theory can be applied to the translation of cosmetic brand names. It studies translation strategies of cosmetic brand names as well. Part five concludes the thesis, making a summary of researching findings and limitations in this thesis and suggestions for future researches.

\section{Literature Review}

This section firstly makes a review of the development of Skopos Theory. Then the definition and three basic rules of this theory are presented. Analysis is made to evaluate this theory. 


\subsection{Development of Skopos Theory}

Since the 1950s, with new developments in such disciplines as linguistics and literature, more and more theories have been adapted from other disciplines to apply to translation studies (Zhang \& Peng, 2015) [4]. Against this background, the cultural turn came into being. The following decades witnessed the development of Skopos Theory. Katharina Reiss, Hans Vermeer and other translation theorists, studying the factors outside the source text, established and developed Skopos Theory.

\subsection{Definition and Three Rules of Skopos Theory}

Proposed and then developed by such translation theorists like Katharina Reiss, Hans Vermeer, Skopos Theory views translation as a conscious activity that is communicative and cross-cultural (Vermeer, 1989) [5]. Christiane Nord (1997) [6] explained that any form of translation action, as the name suggests, can be regarded as an action. Even translation itself is no exception. Every action has a purpose. The word Skopos is a term used to describe the aim of translation. Skopos Theory also emphasizes the role of the translator, who determines the "purpose" of translation.

Three rules should be followed in translation according to Skopos Theory. They are the skopos rule, the coherence rule and the fidelity rule and the skopos rule is the primal rule for translation (Reiss \& Vermeer, 1984) [7]. Intra-textual coherence is assumed to exist to make the translated text meaningful to the receiver (Nord, 1997) [6]. The fidelity rule holds that the translation represents the original and is somehow related to the skopos (Mundy, 2001) [8]. According to Vermeer, the information provided by a translation should be relevant to the original text. Vermeer calls this relationship inter-textual coherence or fidelity (Nord, 1997) [6].

\subsection{Strengths and Limitations of Skopos Theory}

Skopos Theory broke the two-thousand-year-old theoretical chain of dichotomy, shifting the emphasis of translation from a linguistic level to a cultural level. Itallows translators to get rid of the bondages of dichotomy like literal translation and free translation, thus being worshipped as the golden rule to follow. It emphasizes the role of translators, who can choose translation methods according to the aim of translation activity. But this theory also has some limitations. On the one hand, this theory is mainly applied to the business text type and the feasibility of applying the theory on literary translation is still in doubt. On the other hand, Skopos Theory only pays much attention to the aim of the action of translation, neglecting the linguistic nature of the source text.

\section{The Correlation between Skopos Theory and the Translation of Cosmetic Brand Names}

This section mainly talks about the relevance between Skopos Theory and the 
translation of cosmetic brand names. The analysis is conducted from three respects: cosmetic brand name translating as an intentional activity, interpersonal activity, and interpersonal activity.

\subsection{Cosmetic Brand Name Translating as an Intentional Activity}

According to Hans Vermeer, all behaviors are motivated by purposes. Vermeer divided the aim of translation into three categorizations: "the aim of translation in translation process; the function of the translated text and the intention of the style in the discussion of translation and style" (Zhang \& Peng, 2015: 222) [4]. Almost all cosmetic brands having global presence have their brand names translated into another language, mainly English. The translation of cosmetic brand names, accordingly, has three different aims. Firstly, companies' purpose is to increase their sales in other countries. Secondly, translators' aim is to make a living. For these foreign consumers, their purpose is to know more about these products to decide whether or not they will buy them. In conclusion, it can be said that the cosmetic brand name translating is an intentional activity.

\subsection{Cosmetic Brand Name Translating as an Interpersonal Activity}

Justa Holz-Manttari prioritized the translation process and the roles of participants and the situational conditions in which their activities take place (Zhang \& Peng, 2015) [4]. In translating domestic cosmetic brand names, the initiator is the company aiming at attracting the attention of overseas shoppers. The translator is employed to translate brand names from Chinese into English. The user or message receiver is foreign consumers who are expected to know more information about this brand. The translator should not only translate the translation task but also the source text to produce a target text that meets the requirements of the initiator. Under the circumstances, the translator must take into consideration the initiator, the user and the recipient of the message. As a result, the cosmetic brand name translating is an interpersonal activity.

\subsection{Cosmetic Brand Name Translating as an Intercultural Activity}

Eugene Nida said that "Translating means translating meaning" (Nida \& Taber, 1969: 12) [9]. For really successful translation, it is more important to be bicultural than be bilingual because words are meaningful only in the culture. The famous translator and scholar Wang Zuoliang also said that a translator must be a one having a good command of at least two cultures. Skopos Theory assumes that language is embedded in the culture. In translating cosmetic brand names into English, the translator must pay attention to cultural differences, such as religion, moral values, customs, so on and so forth. In so doing, translation can remove some misunderstandings and produce a result intended. In general, cosmetic brand name translation is an intercultural activity. 


\section{The Introduction of Cosmetic Brand Names and Its Translation}

This chapter is divided into five parts: definition of brand names, formation, and significance of cosmetic brand names, the importance of brand name translation and present study in this respect.

\subsection{Definition of Brand Names}

The English word "brand" comes from the word "brand" in Norse, which means to brand something (Li, 2019) [10]. A brand consists of two parts: brand name and brand mark. Take the McDonald's as an example. McDonald's is its brand name while the yellow logo "M" is its brand mark.

A brand name is what a producer gives its products, making its products distinguished from similar products of other producers (Paul Procter, 1988) [11].

Philip Kotler (2017) [12] regarded the brand as a name, symbol or design, or a combination of them, which is used to differentiate the product or service of a seller from that of a competitor.

\subsection{Formation of Cosmetic Brand Names}

The formation of cosmetic brand names can be divided into several types. It may be named after a person, such as Chanel, Arden and Dior, which are chosen from the name of their founder Gabrielle Bonheur Chanel, Elizabeth Arden and Christian Dior respectively. A brand may be named after a place, with Lancome as a representative, which comes from Lancome, a castle on the Luka River in central France. It may be named after its function, like Clean \& Clear, which means that it can make our face clean and clear.

\subsection{Significance of Brand Names}

The significance of brand names has already been realized for a long time. David A. Aaker (1991) [13], a well-known professor of brand management, explains the relationship among the brand name, logo and slogan in his book Managing Brand Equity in the $20^{\text {th }}$ century. Robert Goizueta, the CEO of Coca-Cola once said, our factories and equipment may all be burned down tomorrow, but our brand value will never be destroyed.

Brand names can be regarded as important intangible assets, which can earn recognition for the company. The marketing will depend on the competition of brand names in the days to come.

\subsection{Importance of Brand Name Translation}

The translation of a brand name is as vital as its original name. A well-translated brand name can help it arouse consumers' curiosity and grow in popularity in overseas markets. Take the translation of “佰草集” as an example. It is translated into Herborist in English. For thousands of years, Chinese women have been using the herb for beauty and skincare. Its Chinese brand name means that it can maximize the benefits of difficult herbal medicinein order to make you 
beautiful forever. Its English translation Herborist implies that it is made from herbs and that it can protect our skin, which is an example of appropriate translation.

\subsection{Present Study on the Translation of Cosmetic Brand Names}

Many theses on the translation of cosmetic brand names can be found in China National Knowledge Infrastructure (Zhou \& Yu, 2020 [14]; Liu, 2019 [15]; Zhou \& Tang, 2019 [16]). In CNKI database, with "cosmetics translation" as the subject of retrieval, 152 related literatures can be obtained. If different keywords, such as the translation of cosmetic instructions, cosmetic trademark translation and so on, are used as the subject of retrieval, more related literature can be found. In these literatures, it is found that the main content of these documents is written from three perspectives, namely, translation methods and strategies of cosmetic brand name, instructions and advertising. He Chuansheng (1977) [17] made a deep analysis of brand names in his book Brand Name English from different angles such as linguistics, social psychology and marketing. In addition, more essays on this field can be found. There are a couple of examples. Du Shuling (2015) [18] completed her paper Analysis of Cosmetic Brand Translation into Chinese from the Perspective of Functional Theories. Zheng Lifang (2010) [19] finished her paper, which is about the evaluation of the translation of cosmetic brand names. Based on the researches of many scholars, this thesis aims at proving practical suggestions for some domestic cosmetic companies.

\section{Application of Skopos Theory to the Translation of Cosmetic Brand Names}

This chapter falls into two parts: the skopos of and strategies adopted in domestic cosmetic brand name translation.

\subsection{The Skopos Theoryin Cosmetic Brand Name Translation}

Katharina Reiss (2000) [20] categorized the function of translation into three types and put forward different translation methods accordingly.

\subsubsection{The Implementation of Informative Function}

In informative texts, the content is the focus of communication. Cosmetic brand name translation must convey the meaning of the source text, allowing the target readers to understand what it means. Take “温碧泉” as an example. Its English translation is Wetherm, a combination of wet and thermal. Both wet and thermal are related to water, which means that it can moisturize your skin. When the target readers see this translation, they can understand the function of this product. If it was translated into "Biouquan" or "A Clean Thermal", target readers would regard it as a foundation instead of a cosmetic product.

\subsubsection{The Implementation of Expressive Function}

For expressive texts, the target text should transmit the sense of beauty of the 
source text. Some Chinese cosmetic brand names are very beautiful, like “美康粉 黛”,which gives readers a sense of elegance. But its English translation "Meikang" fails to express the beauty in its name. When foreign readers see this translation, they cannot grasp the meaning of its enchantment, thus having no appetite for its products.

\subsubsection{The Implementation of Operative Function}

Operative texts are intended to persuade the recipient of the text to act in a certain way. The function of the cosmetic brand name translation is to persuade target readers to buy cosmetics. As a result, the translation of brand names is a matter of much concern in the marketing of this band. Take the translation of “玉泽” as an example. Its English translation is "Doctor Yu”, which indicates what its products can do: to protect our skin like a doctor. Therefore, consumers will be attracted by this brand and buy its products.

\subsection{Strategies in Cosmetic Brand Name Translation under the Guidance of Skopos Theory}

Forty domestic cosmetic brand names and their English translations are collected in this thesis. These statistics are taken from the websites of these cosmetics for the accuracy of their translation. Generally speaking, four strategies can be found in this analysis: literal translation, free translation, transliteration and zero translation strategies. The proportion of different translation strategies is illustrated (Figure 1).

\subsubsection{Literal Translation}

Literal translation is to retain both the content and form of the original text, especially the figures, images and national, local coloring in the original (Ye, 2001) [21]. The focus of literal translation is the delivery of information (Newmark, 2001) [22]. In 40 English translations of domestic cosmetic brand names, 7 adopted the method of literal translation. Take “完美日记” as an example.

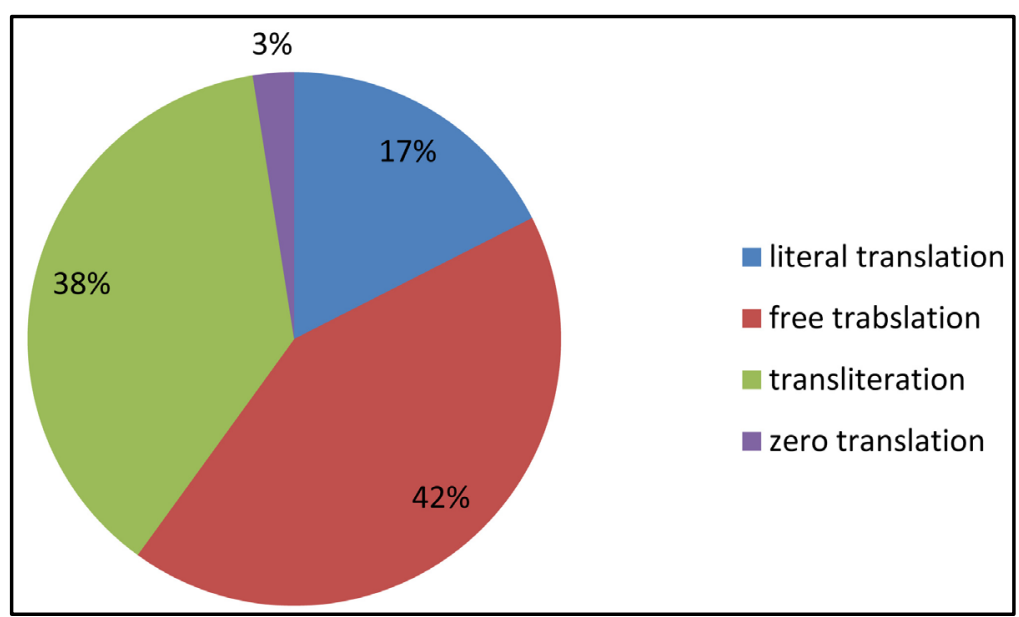

Figure 1. Translation strategies (arranged by the author according to the data used in the paper). 
When it is translated into "Perfect Diary", it implies that the products of this brand can make you perfect all day long. Consumers, women, in particular, will be satisfied with this brand as all women want to make them beautiful and perfect every second. This translation can be seen as a success in the translation of domestic cosmetic products. More examples are below.

$$
\begin{array}{ll}
\text { 小护士-Mininurse } & \text { 水密码-Wetcode } \\
\text { 一叶子-One Leaf Brand } & \text { 维纳斯-Venus } \\
\text { 蜂花-Bee Flower } & \text { 膜法世家 1908-Mask Family } 1908
\end{array}
$$

Literal translation shows the feature of brands, like Mininurse, which mean they can protect your skin like a doctor. Literal translation accounts for about $17 \%$ of the 42 domestic cosmetic brand names analyzed in this thesis. It can be said that literal translation is sometimes used in the translation of domestic cosmetic brand names, but not frequently. The reason is that literal translation is meaningful only when the brand name has a positive meaning in both source culture and target culture. Take the translation of “膜法世家 1908” as an example. It is translated into "Mask Family 1908" in English, which cannot produce on target readers the same effect as on the original readers. Its Chinese name means that this time-honored brand originated in 1908 and that it is a brand of facial masks. But it seems that its English translation, "Mask Family 1908" is the sister drama of Modern Family, rather than a skincare brand. Therefore the translated text must have the same meaning as the original one.

\subsubsection{Free Translation}

Free translation is a kind of meaning-to-meaning translation, which is employed to express the original meaning (Ye, 2001). 17 of 40 brands collected in this thesis adopted free translation. One example is “相宜本草”. It is translated into "Sinoway Herb", which means that it originates in China and that herbs play important roles in its products. Another example is the translation of “丁家宜”, whose translation is "Tjoy". "T" looks like the Chinese word "丁" and "joy" implies that this brand will bring you joy. After using its products, you will be satisfied with it and buy more. More examples are as follows:

$\begin{array}{ll}\text { 佰草集—Herborist } & \text { 珀莱雅—Proya } \\ \text { 百雀羚—Pechoin } & \text { 自然堂—Chando } \\ \text { 稚优泉—Chioture } & \text { 韩束—Kans } \\ \text { 温碧泉—Wetherm } & \text { 玉泽—Doctor Yu } \\ \text { 美加净—MAXAM } & \text { 美素—Museum } \\ \text { 娥佩兰—Opera } & \text { 婷美—Timier } \\ \text { 宠爱之名-For Beloved One } & \text { 丸美—Marubi } \\ \text { 黛妃—Devi } & \end{array}$

Free translation takes a proportion of $42 \%$ of the 40 domestic cosmetic brand names analyzed in this thesis. There is no doubt thatit is used frequently when brand names are translated. Translating is communicating, and this process depends on the reaction of the target audience (Nida \& Taber, 1969) [9]. Free translation was used to bring target readers the same feeling as the original 
reader. The advantage of this approach is that it produces a smooth and expressive translation while retaining the meaning of the original name. But free translation must know limits, otherwise it will be counter-productive. Take the Chinese brand “娥佩兰” as an example. It is translated into "Opera” in Chinese, which is confusing and perplexing as the word "opera" in English refers to a dramatic work or a place that performs opera. In this case, there is no relevance between cosmetic brand names and its translation "Opera".

\subsubsection{Transliteration}

Transliteration is an approach of translation, which translates the word according to their sound and pronunciation. In this thesis, 15 of 40 brand names adopted the method of transliteration. “韩后” is an example. It is translated into "Hanhoo", preserving the musicality of its original name. Here are more examples.

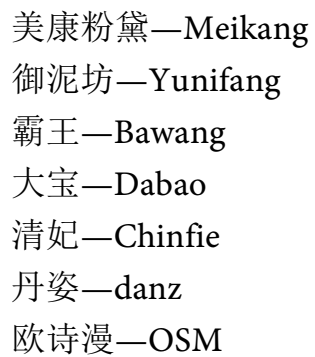

$$
\begin{aligned}
& \text { 安安—Anan } \\
& \text { 馥珮—Fupei } \\
& \text { 隆力奇—longliqi } \\
& \text { 羽西-YUE-SAI } \\
& \text { 巧迪尚惠—Qaodsuhu } \\
& \text { 毛戈平-Mgpin, } \\
& \text { 高夫—Gf }
\end{aligned}
$$

Transliteration takes up $38 \%$ of the 40 domestic cosmetic brand names analyzed in this thesis, second only to free translation. From these examples we can see that there are different transliterations in domestic cosmetic brand name translation. Transliteration can choose to change the pronunciation of the original or not. Such brand names like "Yunifang", "Fupei" and "Bangwang" do not make changes while such names like "YUE-SAI", "Chinfie" and "Qaodusuhu" changes it. By doing so, it can allow the target readers to feel the sonority and musicality of its brand name. But transliteration also has its limits. When translating domestic cosmetic brand names, cultural background must be taken into consideration. Take the translation of “安安” as an example. The word “安安” bears good meaning in Chinese culture, meaning safety and health. But in western culture, "anan" is a monster who poses threats to people. Therefore, usually, target readers will not choose its products. In conclusion, transliteration is a good choice in translating domestic brand names, but we must take into account cultural differences so as to avoid misunderstandings.

\subsubsection{Zero Translation}

Zero translation, or non-translation, is one of the methods adopted in the translation. It refers to the use of a cosmetic brand name in another country without translation. There is only one Chinese brand that uses this method, that is, Face 7 because its name is an English one. However, many domestic brands must be translated. Otherwise, foreign consumers cannot understand their meaning at all. Zero translation accounts for $3 \%$ of the 40 domestic cosmetic brand names 
analyzed in this thesis. It can be said that non-translation is the last method to be used in translating domestic cosmetic brand names. In contrast, zero translation was used by many foreign cosmetic companies, including AHC, NYX, Only, etc. It can be partly attributed to the growing popularity of English, thus almost every young Chinese know a little English. More examples are listed in the following part.

$\begin{array}{ll}\text { Canmake } & \text { The Ordinary } \\ \text { VOV } & \text { HR } \\ \text { UP2U } & \end{array}$

\section{Conclusions}

Through the analysis, the author illustrates what Skopos Theory is and why there is relevance between Skopos Theory and the translation of domestic cosmetic brand names. Having studied the translation of 40 domestic cosmetic brand names, the author introduces different methods of translation and their strengths and limitations. In this thesis, after analyzing four translation methods, the author finds that free translation is the dominant method, which takes up the largest proportion in all the methods discussed. These strategies provide translators with some instructions for how to translate domestic cosmetic brand names according to their characteristics and purposes in an effective way.

Compared with other analyses in this field, this thesis covers a scope that is relatively narrow as it only emphasizes the translation of domestic cosmetic brand names from the perspective of Skopos Theory. In so doing, the author wants to provide more detailed guidance to domestic cosmetic companies when it comes to the translation of their brand names. This thesis, however, bears obvious limitations.

Firstly, only 40 domestic cosmetic brand names are mentioned and analyzed in this thesis, which cannot reflect the whole picture of domestic cosmetic brand name translation. Secondly, these brand names are chosen at random and the division of translation strategies is made by the author, which is not convincing enough. Thirdly, without a good command of marketing, translation studies and economy, the translator cannot give a completely right analysis on the translation of cosmetic brand names and their influence in overseas markets. With an aim to going further in this field, the author will work harder in the future.

The suggestions on further studies of translation of domestic cosmetic brand names are as follows:

First, more statistics are expected to be collected in order to cover the entire landscape of the domestic cosmetic community. Second, the author herself divides the translation of domestic cosmetic brand names into different types based on her understanding, which lacks evidence. More opinions from experts are needed so as to make a clear and right division. Third, in this study, the strengths and limitations of different translation strategies are summarized by the author, which is not convincing. If conditions allow, the author can design a 
questionnaire targeted at foreign consumers in the future, which can help us understand how they like these translations.

\section{Conflicts of Interest}

The author declares no conflicts of interest regarding the publication of this paper.

\section{References}

[1] Xie, F.S., Gao, L. and Xie, P.Y. (2019) Supply Side Structural Reform from the Perspective of Global Production Network. Management of the World, No. 11, 89-101.

[2] Zhang, J.Y. (2020) Analysis of Coca Cola's Marketing Strategy. Foreign Investment in China, No. 17, 13-15.

[3] Zhong, L. (2016) Analysis on the Success Factors of Coca Cola Company. The Modernization of Business, No. 12, 30-31.

[4] Zhang, Z. and Peng, F.S. (2015) A Concise Course of Chinese and Western Translation Theory. Tsinghua University Press, Beijing.

[5] Vermeer, H.J. (1989) Skopos and Commission in Translational Action. World Publishing Corporation, Shanghai.

[6] Nord, C. (1997) Translation as a Purposeful Activity, Functionalist Approaches Explained. St. Jerome Publishing, Manchester.

[7] Reiss, K. and Vermeer, H.J. (1984) Groundwork for a General Theory of Translation. Niemeyer, Tubergen.

[8] Mundy, J. (2001) Introducing Translation Studies: Theories and Practice. Routledge, London and New York.

[9] Nida, E.A. and Taber, C.R. (1969) The Theory and Practice of Translation. Brill Academic Publishers, Leiden.

[10] Li, T.T. (2019) Opinions on Brand Building. Quality Exploration, 14, 77-80.

[11] Procter, P. (1988) Longman Contemporary English-Chinese Dictionary. Modern Press, Beijing.

[12] Kotler, P. (2017) Philip Kotler: Some of My Adventures in Marketing. Journal of Historical Research in Marketing, 9, 203-208.

https://doi.org/10.1108/JHRM-11-2016-0027

[13] Aaker, A.D. (1991) Managing Brand Equity. Free Press, New York.

[14] Zhou, B.Y. and Yu, Y.Q. (2020) Translation Strategies of Foreign Cosmetic Brand Names. Overseas English, No. 20, 90-91.

[15] Liu, Y.J. (2019) Chinese Translation of Cosmetic Brands Based on Functional Equivalence Theory. Cultural and Educational Materials, No. 13, 47-49.

[16] Zhou, X.T. and Tang, Q.L. (2019) A Review of Cosmetic Advertisement Translation in China in the Past Decade. The Aurora Borealis, No. 12, 77-78.

[17] He, C.S. (1997) Trademark English. Hunan University Press, Changsha.

[18] Du, S.L. (2015) Chinese Translation of Cosmetic Brand Names from the Perspective of Functionalist Translation Theory. Beijing Foreign Studies University, Beijing.

[19] Zheng, L.F. (2010) The Linguistic Features of Cosmetic Product Names and the Pros and Cons of Translation. Journal of Xichang College, 17, 28-32.

[20] Reiss, K. (2000) Type, Kind and Individuality of Text: Decision Making in Transla- 
tion. In: Venuti, L., Ed., The Translation Studies Reader, Routledge, London and New York, 160-171.

[21] Ye, Z.N. (2001) Advanced English-Chinese Translation Theory and Practice. Tsinghua University Press, Beijing.

[22] Newmark, P. (2001) Approaches to Translation. Shanghai Foreign Language Education Press, Shanghai. 